\title{
Psychological and psychosocial interventions for negative symptoms in psychosis: systematic review and meta-analysis
}

Danyael Lutgens, Genevieve Gariepy and Ashok Malla

\begin{abstract}
Background
Negative symptoms observed in patients with psychotic disorders undermine quality of life and functioning. Antipsychotic medications have a limited impact. Psychological and psychosocial interventions, with medication, are recommended. However, evidence for the effectiveness of specific non-biological interventions warrants detailed examination.
\end{abstract}

\section{Aims}

To conduct a meta-analytic and systematic review of the literature on the effectiveness of non-biological treatments for negative symptoms in psychotic disorders.

\section{Method}

We searched for randomised controlled studies of psychological and psychosocial interventions in psychotic disorders that reported outcome on negative symptoms. Standardised mean differences (SMDS) in values of negative symptoms at the end of treatment were calculated across study domains as the main outcome measure.

\section{Results}

A total of 95 studies met our criteria and 72 had complete quantitative data. Compared with treatment as usual cognitive-behavioural therapy (pooled SMD -0.34 , $95 \% \mathrm{Cl}-0.55$ to -0.12 ), skills-based training (pooled SMD $-0.44,95 \% \mathrm{Cl}-0.77$ to -0.10 ), exercise (pooled SMD $-0.36,95 \% \mathrm{Cl}-0.71$ to -0.01$)$, and music treatments (pooled SMD $-0.58,95 \% \mathrm{Cl}-0.82$ to -0.33 ) provide significant benefit. Integrated treatment models are effective for early psychosis (SMD $-0.38,95 \% \mathrm{Cl}-0.53$ to -0.22 ) as long as the patients remain in treatment. Overall quality of evidence was moderate with a high level of heterogeneity.

\section{Conclusions}

Specific psychological and psychosocial interventions have utility in ameliorating negative symptoms in psychosis and should be included in the treatment of negative symptoms. However, more effective treatments for negative symptoms need to be developed.

\section{Declaration of interest}

None

\section{Copyright and usage}

(c) The Royal College of Psychiatrists 2017.
Negative symptoms, characterised by an absence or reduction of affective, as well as social and behavioural expression, are regarded as an inherent aspect of psychotic disorders and among the most important predictors of quality of life ${ }^{1}$ and functional outcome. ${ }^{1-3}$ Further, negative symptoms may be transitory and secondary to depression and side-effects from antipsychotic medication, ${ }^{4}$ whereas persistent negative symptoms are often regarded as primary to the underlying disease process. ${ }^{4}$ Persistent negative symptoms are present in $25 \%$ of patients with first-episode psychosis $(\mathrm{FEP})^{5}$ and in an even greater proportion of patients with chronic schizophrenia. ${ }^{6,7}$ Antipsychotic medications, highly effective for the treatment of positive symptoms, and newer biological treatments such as transcranial magnetic stimulation, have at best a modest impact on negative symptoms. ${ }^{8}$ Given the paucity of options available to treat negative symptoms, current best practice suggests the use of psychological and psychosocial interventions in addition to medication. ${ }^{9,10}$ The evidence supporting the effectiveness of such interventions for negative symptoms has, however, not been fully explored. Reviews on psychological and psychosocial treatment options have focused largely on positive symptoms and relapse prevention ${ }^{11-14}$ with two exceptions ${ }^{15,16}$ that presented negative symptom outcomes as their primary objective. In their meta-analysis, Fusar-Poli and colleagues ${ }^{15}$ pooled negative symptom outcomes from a broad range of primarily biological and some psychological interventions. They aggregated all negative symptom outcome data from a limited number of psychological interventions into a single effect size, limiting the interpretation for different psychological and psychosocial treatments. In a narrative analysis of results of randomised control trials (RCTs) of psychological interventions with negative symptom outcomes, ${ }^{16}$ alternative intervention types such as arts- and exercise-based therapies were excluded and a stringent systematic review of the literature including quality ratings was not performed. Our study extends previous work by providing a systematic review and complete qualitative and quantitative synthesis of the current literature on the effectiveness of all psychological and psychosocial interventions for the treatment of negative symptoms in psychotic disorders.

\section{Method}

\section{Search strategy}

We searched the following five major databases: MEDLINE via PubMed, Embase, Web of Science, PsycINFO and the Cochrane Library. Articles from inception to 19 October 2015 were included in our search. Database-specific search terms included the key words 'psychosis', 'schizophrenia', 'negative symptoms', 'therapy' and 'intervention' with diagnosis-specific and symptom-specific subtypes and relevant variations and synonyms (online supplement DS1). We searched only English-language publications and identified additional studies through hand searches of bibliography from primary studies, review articles and key journals, as well as through contacts with experts in the field (Fig. 1). 


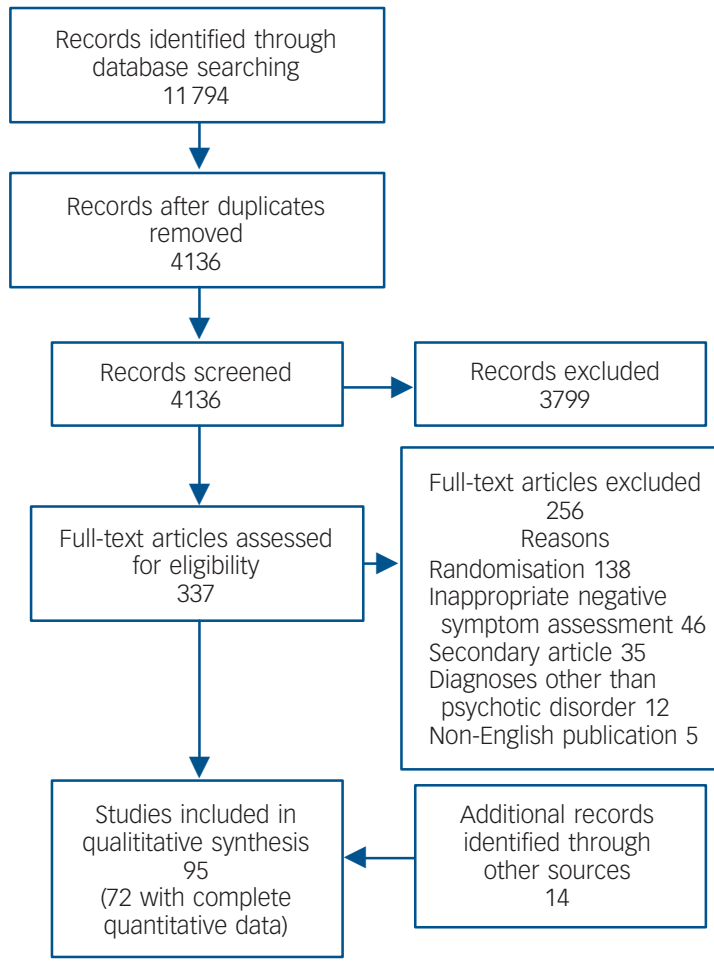

Fig. 1 PRISMA flow diagram.

\section{Inclusion/exclusion criteria}

Studies were included if they met the following criteria: RCT design; investigation of a psychological or psychosocial intervention; report of negative symptom outcomes using a valid and reliable negative symptom measurement (such as the Scale for Assessment of Negative Symptoms (SANS), the Negative Symptom subscale of the Positive and Negative Symptom Scale (PANSS)); a majority sample with a diagnosis of a schizophrenia spectrum or other non-organic psychotic disorder. Random crossover trials were included, although only between-group comparisons data, prior to the crossover, were extracted. We excluded the following types of studies: those published in a language other than English; quasi-experimental study designs; theoretical papers; case studies; meta-analyses; other reviews; qualitative reports and designs utilising cluster random trials as well as medication efficacy trials even if the latter used a psychological or psychosocial intervention as a supplementary treatment.

\section{Screening}

The first author (D.L.) and a research assistant independently screened all citation titles for their broad applicability using computer-based software (Distiller $\mathrm{SR}^{17}$ ). Titles that clearly did not meet inclusion criteria were removed from citation listings. At the second stage a more detailed independent screening by both raters was conducted on all abstracts. Disagreements at both the first and second screening were resolved between the first author (D.L.) and research assistant through discussion with the senior author (A.M.). The first author (D.L.) extracted the full texts of selected articles for the final screening (Fig. 1).

\section{Data extraction and quality assessment}

Information on the nature of the experimental intervention and control, characteristics of the study sample, outcome measures and effect sizes were extracted. Study quality was assessed from a critical appraisal checklist. ${ }^{18-21}$ on standardisation of treatment, recruitment, sequence generation, allocation concealment, comparability of groups, equality of care between groups, masked assessment, inclusion/exclusion criteria, attrition, adherence and intention-to-treat analysis. Studies were considered to be of poor quality if they presented high or unclear risk of bias for either the sequence generation or allocation concealment, or presented two or more risks of bias. Sample size was not included within the measure of quality. Disagreements on quality were resolved by discussion among authors (D.L., G.G. and A.M.).

\section{Quantitative analysis}

A quantitative summary of the literature was obtained through meta-analytic methods. Measures of effect were calculated from data available or from standard errors reported ( $n=72$ studies). Standard mean difference (SMD) reported, or Cohen's $d$ can be interpreted such that $0.2,0.5$, and 0.8 are equated with effect sizes of small, medium, and large. ${ }^{22}$ Studies for which such data were not available were included in the qualitative analysis only. We pooled estimates using the DerSimonian \& Laird random-effects model. High heterogeneity between studies was expected and evaluated through $I^{2}$ tests as well as through stratified analysis by type of intervention, control and study quality. Publication bias was determined with a funnel plot that provides a visual representation of how the odds ratio for each individual study varied from the pooled odds ratio. Analyses were conducted in Stata 12.1. No data of negative symptom outcomes for controls within treatment as usual (TAU) and waitlist conditions post treatment end are included in this review. Several RCTs included either two active controls or an active control alongside a TAU group. In such cases, for the overall pooled effect size, we included only the TAU group as this was the comparison control used most often across studies. Post-treatment follow-up data are described qualitatively. The PRISMA checklist was followed for the reporting of all outcomes. ${ }^{23}$ The protocol for this review is available on PROSPERO (CRD42014015244).

\section{Results}

\section{Study selection}

A total of 11794 publications were initially retrieved and, after removing duplicates and adding studies from hand searches, 4150 publication citations remained for broad screening. A further 3799 studies were excluded. Pharmacological trials and studies without a randomisation design were the main reasons for exclusion. A total of 95 studies that met the inclusion criteria were thus identified (Fig. 1). ${ }^{23}$ Of these, 72 studies provided data on negative symptom outcome and were included in the meta-analysis.

\section{Cognitive-behavioural therapies (СВT)}

A total of 26 studies investigated the effectiveness of CBT in psychosis. ${ }^{24-53}$ Of these, two were CBT interventions adapted specifically for treating negative symptoms. ${ }^{28,29,39}$ Highly significant heterogeneity between CBT studies was found, $I^{2}=73.6 \%$, $P<0.001$ (online Table DS1). Details of study characteristics are presented in Table DS2. Treatment was offered over a mean of 6 months (range 1.25-18) for a mean of 28 sessions, each session lasting a mean of $66 \mathrm{~min}$ (range 45-90).

Overall, evidence indicated CBT to be an effective intervention for negative symptoms (pooled SMD $-0.34,95 \%$ CI -0.55 to -0.12 , Fig. 2(a)). Compared with TAU, 59\% (10/17) of studies reported CBT to be more effective at the end of treatment (pooled 
SMD $-0.43,95 \%$ CI -0.55 to -0.30$)$. Compared with active control, none of 12 studies suggest a benefit of CBT (pooled SDM $-0.11,95 \%$ CI -0.26 to 0.04 ), although 7 reported substantial but equal improvements in both active conditions. For studies that reported long-term follow-up (mean 27 months), CBT was beneficial compared with TAU across 57\% (8/14) of the comparisons. None of the studies with active controls reported such effect, except for one using befriending as the active control. ${ }^{31,54}$ There were no differences in effects as a result of differences in study quality.

\section{Skills training, occupational therapy and cognitive adaptation training}

A total of 17 RCTs using skills training $(n=11),{ }^{55-65}$ occupational therapy $(n=3),{ }^{66-68}$ cognitive adaptation training $(n=2)^{69,70}$ or vocational training $(n=1)^{71}$ were included. Only one study was designed specifically to treat negative symptoms ${ }^{65}$ and there was highly significant heterogeneity between studies, $I^{2}=85.8 \%$, $P<0.001$ (online Table DS1). Study characteristics are available in Table DS3. Treatment was offered over a mean of 7 months (range 1.5-24) for a mean of 25.5 sessions (range 12-76) with a mean length of $86 \mathrm{~min}$ per session (range 45-180). One active control study compared two variations of skills training: social skills and relapse prevention skills. ${ }^{58}$

Overall $53 \%(9 / 17)$ of the studies favoured the experimental intervention at the end of treatment (pooled SMD $-0.44,95 \%$ CI -0.77 to -0.10 , Fig. 2(a)). This effect was largely driven by studies using TAU as the control (pooled SMD $-0.42,95 \%$ CI -0.56 to -0.28 ) and was not present in studies using an active control (pooled SMD $-0.05,95 \%$ CI -0.30 to 0.19 ). Stratified analyses indicated a significant effect of skills training (pooled SMD $-0.31,95 \%$ CI -0.45 to -0.17$)$ and of occupational therapy (pooled SMD $-1.00,95 \% \mathrm{CI}-1.48$ to -0.51 ) only. In the study that compared different skills-training programmes, no significant differences were reported. ${ }^{58}$ High- and mediumquality studies reported more favourable outcomes (pooled SMD $-0.42,95 \%$ CI -0.56 to -0.28 ) than those of low quality (pooled SMD 0.00, 95\% CI -0.26 to 0.26 ). Of five studies with follow-up negative symptom data, ${ }^{57,61-63,69}$ three favoured the experimental intervention at 1 month, ${ }^{63} 3$ months ${ }^{61}$ and 6 months. ${ }^{62}$ The benefit of skills training over social milieu therapy that was reported at 3 months was not maintained at 6-month follow-up in one study. ${ }^{61}$

\section{Neurocognitive therapies}

A total of 16 studies used neurocognitive interventions including cognitive remediation $(n=11) ;{ }^{72-82}$ cognitive training $(n=2) ;{ }^{83,84}$ cognitive rehabilitation $(n=1) ;{ }^{82}$ neurocognitive therapy $(n=1) ;{ }^{85}$ and cognitive enhancement $(n=1) .{ }^{86}$ Another study focused on improving cognitive strategies related to attention, verbal memory and planning. ${ }^{87}$ Three interventions studied were designed primarily to improve negative symptom outcomes ${ }^{76,83,87}$ (see online Table DS4 for study characteristics). There was highly significant heterogeneity between studies, $I^{2}=74.2 \%, P<0.001$ (online Table DS1). Across studies, treatment was offered over a mean of 3.75 months (range 2-24) with a mean of 42 sessions (range 16-120), delivered for a mean of $76 \mathrm{~min}$ (range 15-150). Seven studies utilised computer technology for treatment delivery $77,78,80-82,86,87$ including two specifically designed for the amelioration of negative symptoms. ${ }^{83,87}$ Active controls included computer games ${ }^{81}$ and supportive therapy. ${ }^{86}$

Neurocognitive interventions were effective in only a minority of studies $(n=5,31 \%)$ and data show no overall effect (pooled SMD $-0.15,95 \%$ CI -0.41 to 0.11 , Fig. 2(b)), regardless of control type and/or study quality. No significant differences were found between modes of neurocognitive treatment delivery. ${ }^{78,87}$ Two of five studies with long-term follow-up data ${ }^{72-74,77,87}$ reported a significant effect at 3 months ${ }^{84}$ and 9 months, ${ }^{85}$ and another study reported a significant benefit of cognitive remediation at 4- but not at 9-month follow-up, compared with group leisure activities. $^{72}$

\section{Exercise therapy}

Ten RCTs of exercise therapy on negative symptoms ${ }^{88-97}$ were reported (see online Table DS5 for study characteristics). Exercises investigated were yoga, ${ }^{89,90,92,94}$ aerobic, ${ }^{91,93}$ resistance training, ${ }^{97}$ structured walking, tai chi ${ }^{88}$ and traditional dance. ${ }^{96}$ Of these only one study was designed to measure negative symptoms as a primary outcome. ${ }^{88}$ Significant heterogeneity between studies was found, $I^{2}=54.8 \%, P=0.039$ (online Table DS1). Exercises were offered over a mean of 3 months (range 2 weeks to 8 months) with an average of 26.7 sessions (range 8-48) and a mean of 53 min per session (range 40-60).

An effect of exercise on negative symptoms was found (pooled SMD $-0.36,95 \%$ CI -0.71 to -0.01 , Fig. $2(\mathrm{~b})$ ) that was largely the result of four of seven (57\%) comparisons with TAU (pooled SMD $-0.42,95 \%$ CI -0.76 to -0.09 ) whereas active control comparisons showed no effect (pooled SMD -0.07 , 95\% CI -0.37 to 0.23 ). Overall, lower-quality studies showed greater effects (pooled SMD $-0.37,95 \%$ CI -0.74 to -0.00 ) than higher-quality studies (pooled SMD $0.14,95 \%$ CI -0.42 to 0.14 ). Resistance training and exercise as active control comparisons were equally effective in treating negative symptoms. ${ }^{97}$ Too few studies were available to warrant a comparison of differences in exercise intervention types. None of the three studies with follow-up assessments found any treatment effect at 1 month, ${ }^{92}$ 1.5 months $^{88}$ and 3 months. ${ }^{94}$

\section{Art and music therapies}

Seven RCTs were art- or music-based interventions: two fine $\operatorname{arts}^{98,99}$ and five music based ${ }^{100-104}$ (see online Table DS6 for study characteristics) with highly significant heterogeneity between studies, $I^{2}=94.9 \%, P<0.001$ (online Table DS1). Treatment was offered over a mean of 4.25 months (range 1-12 months), for a mean of 22 sessions (range 10-52) with a mean of 62.5 min (range 45-90) per session.

Considered together, arts-based treatments were not effective at treating negative symptoms with $57 \%$ (4/7) demonstrating no effect (pooled SMD $-0.14,95 \%$ CI -0.78 to 0.50 , Fig. 2(b)). However, whereas fine-arts-based therapies were not advantageous (pooled SMD 0.57, 95\% CI 0.41-0.74), sensitivity analysis revealed a distinct benefit of music-based therapies compared with TAU (pooled SMD $-0.58,95 \%$ CI -0.82 to -0.33 ). ${ }^{101,103,104}$ There were no differences in end-of-study outcomes as a result of differences in study quality. Three studies with follow-up data reported no significant lasting ${ }^{99,104}$ or emerging ${ }^{98,99}$ benefit.

\section{Family-based interventions}

Six RCTs investigating family-based interventions reported negative symptom outcomes ${ }^{105-110}$ (see online Table DS7 for study characteristics) with marginally significant heterogeneity between studies, $I^{2}=65.4 \%, P<0.056$ (online Table DS1). The mean duration of treatment was 10.9 months (range 2.5-18) with a mean of 23 sessions (range 10-45) and the mean session duration of $97.5 \mathrm{~min}$ (range $60-120) .{ }^{105,106,108,110}$ One study did not provide standardised treatment ${ }^{106}$ and two did not specify. ${ }^{109,110}$ Family interventions were delivered within: multiple 
Author

Cognitive-behavioural

Barrowclough et al (2006) ${ }^{35}$

Cather et al (2005) ${ }^{36}$

Farhall et al (2009) ${ }^{24}$

Granholm et al (2014) ${ }^{25}$

Gumley et al (2003) 26

Hall \& Tarrier $(2003)^{40}$

Jackson et al $(2008)^{27}$

Krakvik et al (2013) ${ }^{41}$

Li et al (2015) $)^{45}$

Lincoln et al (2012) ${ }^{46}$

Morrison et al (2014) ${ }^{30}$

Peters et al (2010) ${ }^{48}$

Rector et al (2003) ${ }^{49}$

Startup et al (2005) $)^{50}$

Tarrier et al (2004) ${ }^{51}$

Valmaggia et al (2005) ${ }^{53}$

Subtotal

Skills training, occupational

therapy and cognitive

adaptation therapy

Bartels et al $(2014)^{55}$

Bio \& Gattaz (2011) $)^{71}$

Cook et al (2009) ${ }^{66}$

Foruzandeh

et al (2013) 68

Hansen et al (2012) ${ }^{69}$ Horan et al (2010) ${ }^{58}$

Li \& Wang (1994) $)^{60}$

Lin et al $(2013)^{63}$

Roberts et al (2014) ${ }^{57}$

Rus-Calafell et al (2013) ${ }^{65}$

Sanz et al (2009) ${ }^{64}$

Valencia $(2007)^{56}$

Xiang et al (2006) ${ }^{62}$

Subtotal

NOTE: Weights are from

random-effects analysis

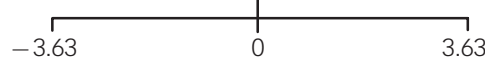

Favours intervention Favours control
Standardised

mean differences (95\% Cl)

-0.06 ( -0.43 to 0.31$)$
-0.01 ( -0.75 to 0.73$)$
$0.30(-0.11$ to 0.71$)$
$-0.23(-0.56$ to 0.09$)$
$-0.35(-0.68$ to -0.02$)$
$-1.77(-2.71$ to -0.83$)$
$-0.45(-0.95$ to 0.06$)$
$-0.54(-1.13$ to 0.06$)$
$-0.17(-0.45$ to 0.12$)$
$0.11(-0.34$ to 0.55$)$
$-0.79(-1.27$ to -0.32$)$
$-0.31(-0.76$ to 0.15$)$
$-0.50(-1.12$ to 0.12$)$
$-0.64(-1.06$ to -0.21$)$
$-0.94(-1.23$ to -0.65$)$
$0.37(-0.16$ to 0.90$)$
$-0.34(-0.55$ to -0.12$)$

$-0.41(-0.71$ to -0.12$)$

$-0.18(-0.55$ to 0.19$)$

$0.47(-0.17$ to 1.11$)$

$-2.90(-3.63$ to -2.17$)$

-0.08 ( -0.58 to 0.42$)$

0.28 ( -0.03 to 0.58$)$

$-0.92(-1.49$ to -0.35$)$

$-0.15(-0.54$ to 0.25$)$

$-0.13(-0.61$ to 0.35$)$

$-0.36(-0.93$ to 0.21$)$

$-0.18(-1.23$ to 0.87$)$

$-0.82(-1.24$ to -0.41$)$

$-0.66(-1.07$ to -0.25$)$

$-0.44(-0.77$ to -0.10$)$

(b)

Author

Standardised

mean differences

(95\% Cl)

Neurocognitive therapies

Ahmed et al (2015) ${ }^{81}$

Belluci et al $(2003)^{82}$

Cella et al $(2014)^{73}$

Farreny et al (2012) ${ }^{72}$

Gharaeipour

\& Scott $(2012)^{76}$

Holzer et al (2013) ${ }^{80}$

Mueller et al (2015)

Nemoto et al (2009) ${ }^{83}$

Ostergaard et al (2014) ${ }^{77}$

Penades et al $(2006)^{74}$

Sanchez et al $(2014)^{75}$

Tan et al (2015) ${ }^{79}$

vauth et al (2005) ${ }^{87}$

Vita et al $(2011)^{78}$

Subtotal

Exercise therapy

Acil et al (2008)

Cassilhas et al (2015) ${ }^{97}$

Ho et al (2012) ${ }^{88}$

Ikai et al (2014) ${ }^{89}$

Kaltsatou et al (2015) ${ }^{96}$

Manjunath et al (2013) ${ }^{92}$

Scheewe et al $(2013)^{93}$

subtotal

Art and music therapies

Crawford et al (2012) ${ }^{98}$

Lu et al (2013) ${ }^{104}$

Montag et al (2014) ${ }^{99}$

Talwar et al (2006) ${ }^{100}$

Tang et al (1994)103

Ulrich et al (2007) ${ }^{102}$

Crawford (2012) ${ }^{98}$

Subtotal

Family-based intervention

Bradley et al (2006) ${ }^{105}$

Calvo et al (2014) ${ }^{108}$

Dyck et al (2000) ${ }^{107}$

Subtotal

\section{Miscellaneous interventions}

Garety et al (2006) ${ }^{114}$

Gelkopf et al (2006) $)^{112}$

Gholipour (2012) ${ }^{119}$

Rohricht \& Priebe (2006)

Villalta-Gil et al (2009) ${ }^{11}$

White et al (2011) ${ }^{115}$

Subtotal

NOTE: Weights are from

random-effects analysis
$-0.19(-0.63$ to 0.26$)$

-0.57 ( -1.26 to 0.12$)$

$0.02(-0.40$ to 0.45$)$

-0.19 ( -0.70 to 0.31$)$

$-1.83(-2.55$ to -1.10$)$

$0.15(-0.55$ to 0.85$)$

0.65 ( -0.33 to 0.97$)$

$-1.10(-2.13$ to 0.07$)$

-0.05 ( -0.41 to 0.31$)$

-0.11 ( -0.73 to 0.51$)$

-0.09 ( -0.51 to 0.32$)$

0.19 ( -0.20 to 0.57$)$

-0.15 ( -0.56 to 0.25$)$

$0.10(-0.44$ to 0.63$)$

-0.15 ( -0.41 to 0.11$)$

-1.25 ( -2.03 to 0.46$)$

$-1.02(-1.86$ to -0.18$)$

$-0.63(-1.36$ to -0.11$)$

$-0.13(-0.69$ to 0.42$)$

-0.05 ( -0.76 to 0.65$)$

$-0.12(-0.54$ to 0.29$)$

0.11 ( -0.38 to 0.61$)$

$-0.36(-0.71$ to -0.01$)$

$0.14(-0.09$ to -0.38$)$

$-0.15(-0.96$ to -0.07$)$

-0.24 ( -0.76 to 0.28$)$

$-0.30(-0.74$ to 0.15$)$

$-1.08(-1.56$ to -0.60$)$

$-0.40(-1.06$ to 0.25$)$

-1.30 (1.04 to 1.56$)$

-0.14 ( -0.78 to 0.50$)$

$0.38(-0.18$ to 0.94$)$

$-0.42(-0.95$ to 0.12$)$

$-0.46(-0.96$ to 0.04$)$

-0.19 ( -0.70 to 0.34$)$

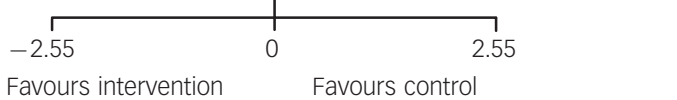

\section{Fig. 2 Forest plots.}

(a) Cognitive-behavioural therapy, skills training, occupational therapy and cognitive adaptation therapy; (b) neurocognitive therapies, exercise therapy, art and music therapies, family-based interventions and miscellaneous interventions.

family groups, ${ }^{106,107,109}$ single family groups ${ }^{110}$ or a combination of both. ${ }^{105,108}$ One study also used individualised sessions of psychotherapy. ${ }^{109}$ All studies focused primarily on providing psychoeducation; ${ }^{105-109}$ two studies also included large components of social-skills training. ${ }^{106,110}$ Only one study was designed to measure negative symptom outcomes. ${ }^{107}$

No effect of family intervention was detected either individually or overall (pooled SMD $-0.19,95 \%$ CI -0.70 to 0.34 ) regardless of control comparison. There were no differences in end-of-study outcomes as a result of differences in study quality. Neither of the two studies with follow-up reported a significant effect. ${ }^{109,110}$

\section{Miscellaneous interventions}

The following unclassified interventions $(n=10)$ were included: humour therapy $(n=2) ;{ }^{111,112}$ specialised early intervention for FEP (SEI: $n=2) ;^{113,114}$ acceptance and commitment therapy $(n=1) ;{ }^{115}$ body psychotherapy $(n=1) ;{ }^{116}$ dog-assisted psychological 
treatment $(n=1) ;{ }^{117}$ adherence therapy $(n=1) ;{ }^{118}$ token therapy $(n=1) ;^{119,120}$ and motivation approach to learning arithmetic $(n=1){ }^{120}$ Body psychotherapy, motivational learning and humour therapy were designed specifically to treat negative symptoms (see online Table DS8 for study characteristics). Heterogeneity between studies was found to be non-significant, $I^{2}=33.3 \%, P=0.174$ (online Table DS1). The mean duration of treatment was 2.25 months (range 1-3), excluding both SEI studies that were conducted over a span of 1.5 years ${ }^{114}$ and 2 years. ${ }^{113}$ Whereas SEI interventions were intensive over the entire period of 1.5-2 years, for the other studies mean number of sessions offered was 24 (range 8-60) over an average session length of 66 min (range 30-120).

A significant effect of all miscellaneous studies was found (pooled SMD $-0.42,95 \%$ CI -0.77 to -0.07 , Fig. 2(b)) driven largely by TAU as opposed to active control comparisons (pooled SMD $-0.48,95 \%$ CI -0.75 to -0.21 ; pooled SMD $-0.33,95 \%$ CI -0.67 to 0.02 , respectively). Higher-quality studies reported greater overall effects (pooled SMD $-0.61,95 \%$ CI -0.87 to -0.36) compared with low-quality studies (pooled SMD 0.08, $95 \%$ CI -0.37 to 0.52 ). Compared with supportive counselling, body psychotherapy was found to be more effective and the effect was retained at 4-month follow-up (pooled SMD $-0.74,95 \%$ CI -1.35 to -0.13$).{ }^{116}$ Token therapy was more effective than TAU (pooled SMD $-0.91,95 \%$ CI -1.66 to -0.15 ) but not active control (exercise). Treatment in an SEI service was more effective than TAU (regular care) (pooled SMD $-0.38,95 \%$ CI -0.53 to -0.22 ) but the effect was not retained after transfer to regular care. ${ }^{121}$ Compared with TAU, adherence therapy ${ }^{118}$ and acceptance and commitment therapy ${ }^{115}$ were not effective. Token therapy was not more effective on negative symptoms than an exercise active control. ${ }^{119}$ Overall, medium- and high-quality studies were more likely to report a significant effect at end of treatment (pooled SMD $-0.61,95 \% \mathrm{CI}-0.87$ to -0.36 ) than were lowquality studies (pooled SMD $0.08,95 \%$ CI -0.37 to 0.52 ).

\section{Additional analyses}

The above results raise several other questions for which we conducted the following additional analyses.

\section{Is the impact of interventions greater in the early $v$. later phases of illness?}

Using study reports of mean patient age as a proxy measure of early $v$. later phase we used a cut-off of 35 years, as indicated by criteria for entrance into early-intervention programmes. ${ }^{122} \mathrm{We}$ found no difference in negative symptom outcomes across those studies with a mean patient age $\leqslant 35$ years (pooled SMD $-0.342,95 \%$ CI -0.528 to -0.156 ) compared with those with a mean patient age $>35$ years (pooled SMD $-0.284,95 \%$ CI -0.520 to -0.048$)$. We also tested this by comparing outcomes for those receiving SEI (pooled SMD $-0.340,95 \%$ CI -0.474 to -0.206$)$ as compared with those treated in other regular services (pooled SMD $-0.304,95 \%$ CI -0.467 to -0.141 ). This also did not reveal any differences in outcome on negative symptoms across the two types of services.

\section{Are there differences in effectiveness of intervention provided in individual $V$. group format?}

An investigation into intervention format revealed no differential effects of group (pooled SMD $-0.31,95 \%$ CI -0.601 to -0.019 ), individual (pooled SMD $-0.313,95 \%$ CI -0.505 to -0.120 ) and combined formats (pooled SMD -0.243 , 95\% CI -0.483 to -0.004$)$.
Does intensity of interventions have an impact on effectiveness?

As psychotherapy is traditionally offered over 45 to $50 \mathrm{~min}$ per week, ${ }^{123}$ we used a cut-off of $45 \mathrm{~min}$ per week as a measure of high $v$. low intensity of treatment. We found that interventions lasting over $45 \mathrm{~min}$ per week were more effective (pooled SMD -0.341 , $95 \%$ CI -0.558 to -0.125$)$ than those offered over less than 45 min per week (pooled SMD $-0.024,95 \%$ CI -0.373 to 0.324 ).

\section{Why might differences in effect of interventions emerge} only when TAU is used as the control condition and not when active controls are used?

The putative mechanisms that might be responsible for the effectiveness of experimental interventions, when compared with TAU as controls, might be similar to those incorporated in some of the active controls used. In order to explore this question, we assigned a putative mechanism of action to each intervention tested based on the content of the intervention: behaviour activation (for example CBT, activity groups, recreation, crafts $^{124,125}$ ), social engagement (for example supportive therapy, befriending ${ }^{126}$ ), skill enhancement (for example skills training, occupational therapy, vocational rehabilitation ${ }^{127}$ ), neurocognitive (for example cognitive remediation, cognitive rehabilitation ${ }^{128}$ ) and non-specific (for example video games ${ }^{91}$ ). We found similar effects from experimental interventions and active controls when the latter utilised one of the following mechanisms of action: skill enhancement (pooled SMD 0.206, CI -0.039 to 0.451 ); behavioural activation (pooled SMD $-0.066,95 \%$ CI -0.257 to 0.124 ); non-specific mechanism of action (pooled SMD $-0.068,95 \%$ CI -0.402 to 0.226 ); social engagement (pooled SMD $-0.276,95 \% \mathrm{CI}-0.608$ to 0.056 ) and neurocognitive (pooled SMD $-0.431,95 \%$ CI -1.48 to 0.618 ).

\section{Publication bias}

Results of the funnel plot used to determine publication bias indicate a large grouping of studies left of the mean, suggesting that those studies reporting negative effects may have been less likely to have been published (online Fig. DS1).

\section{Discussion}

\section{Main findings}

Our meta-analysis and systematic review revealed evidence that negative symptoms can be improved at least modestly with psychosocial and psychological interventions. Although guidelines have traditionally supported the use of CBT, findings from skillsbased interventions (SBIs) suggest that the latter are likely to have comparative, if not enhanced utility, as long as the treatment is continued. Although there is some suggestion for the effectiveness of physical activity and music, study quality for these interventions was generally not satisfactory and higher-quality studies are indicated. The largest number of studies was available in support of CBT and SBI. Overall the quality of most studies was medium.

Across study domains, effect sizes of decrease in negative symptoms over time tended to be small. Only SBIs, CBT, music therapy, exercise, body psychotherapy and SEI demonstrated overall moderate effect sizes, largely in comparison with TAU. Neurocognitive, family-based and humour therapies were not found to be an effective treatment for negative symptoms, even compared with TAU.

Across interventions, we found that skill enhancement and behavioural activation were more successful than TAU in targeting negative symptoms in psychosis. This finding has face validity in 
that improved skills, and particularly social skills, are likely to be associated with increases in prosocial behaviours (and vice versa), that are key indicators of negative symptom improvement. Sensitivity analyses of active control interventions suggest that certain active mechanisms of action are present in both experimental and active controls and, therefore, explain lack of differences in outcome when experimental interventions are compared with active controls. Further, we found that across all experimental interventions, treatment intensity of at least more than 45 min per week is associated with a better outcome. All things being equal, consistency and repetition may partially explain this effect, as may increased social contact. Indeed, we found that group format was as effective as individual format, suggesting some advantages in terms of cost-effectiveness.

\section{Interpretation of our findings}

Most studies available for review were not designed to treat negative symptoms and we used data reported on change in negative symptoms irrespective of the primary outcome for the study. As a result, patients were not selected for their negative symptom status. However, notwithstanding differences in rating scales used, our findings from a large number of CBT and SBI studies allowed adequate data comparisons. The results from these suggest that those with higher levels of negative symptoms on entry undergo the greatest negative symptom improvement. This suggests the utility of CBT and SBIs among populations with high levels of negative symptoms. However, few studies selected patients with high levels of negative symptoms.

The quality of evidence from the majority of studies in this review was at best moderate. Many studies used small samples and did not account for attrition, limiting the power of many studies to detect significant results. Larger CBT and SBI studies were somewhat more likely to report a significant effect of the experimental intervention, suggesting a need for studies of other psychosocial and psychological interventions to be designed with adequate power.

Consistency of findings was difficult to establish. We found much evidence of high heterogeneity across studies. Within intervention categories there was great variation with regard to treatment protocol, population, type of control and measurement used. Despite this, our conclusions of somewhat limited evidence for the effectiveness of psychological and psychosocial interventions are perhaps not surprising, given the nature of negative symptoms and the overall prolonged length of illness of study participants. Treatment success is often dependent upon participation, motivation and communication, ${ }^{129}$ suggesting that greater levels of negative symptoms may preclude the very outcomes being targeted. ${ }^{130}$ That patients were often older, from in-patient settings and chronically ill suggest that they may be struggling from unresolved side-effects from medications, symptoms, social decline and a gradual deterioration of hope that may further challenge treatment outcomes. ${ }^{130}$ In contrast, very few studies included in this review were targeted towards those in the earliest phases of psychosis. Although sensitivity analyses did not indicate any marked difference in negative symptom outcomes according to age, some benefit of younger age, likely reflective of an earlier phase in the course of illness, and treatment in an early-intervention service, was suggested from the data. It is of note that we were limited to utilising study reports of mean patient age that most likely included wide variation with general inclusion criteria of patients aged 18-60/65. Indeed, the encouraging results of SEI with FEP populations ${ }^{13,114}$ confirm the important role of high-quality interventions delivered early on in the course of illness and the role of combined treatments that individually have well-established evidence of efficacy. Further RCTs delivering treatment during this critical period in psychosis may show more promising results.

\section{Limitations}

This meta-analysis and review has several other limitations. Given that virtually all patients across studies continued to be prescribed antipsychotic medications, findings regarding the utility of interventions must be examined within this context of drug therapy. We also excluded non-English language studies, although some studies were conducted outside North America or Europe. We were not able to compare monetary as well as other cost benefits of treatment, including adverse effects, that might further indicate increased utility of any one treatment. The only study ${ }^{29}$ that examined adverse effects, defined as 'suicides, suicide attempts, suicidal crises, and severe symptom exacerbations over a period of 12 months after inclusion in the study' compared CBT with cognitive remediation in a sample of 198 patients with schizophrenia. They found that although there were adverse events over the course of the trial, the difference between groups was not significant and did not suggest a subgroup of patients who might necessitate additional monitoring. Finally, we were also not able to differentiate between treatment effects on specific domains (expressive $v$. motivational) of negative symptoms as well as on primary $v$. secondary negative symptoms. The latter include depression, and the possible side-effects of continued antipsychotic medications that may mask as negative symptoms. ${ }^{131}$ This disentanglement would allow us to determine to what extent interventions were targeting specific areas of negative symptoms as well as enduring primary $v$. secondary and transient negative symptoms. Future intervention studies designed to target and measure negative symptoms in psychosis as a primary outcome may provide greater clarity as to treatment mechanisms and related outcomes. This would eventually assist in designing more effective psychological and psychosocial interventions for treatment of negative symptoms in future.

\section{Danyael Lutgens, MSc, Department of Psychiatry, McGill University, Douglas Ment Health University Institute, Montréal, Quebec; Genevieve Gariepy, PhD, McGill University, Institute for Health and Social Policy, Montréal, Quebec; Ashok Malla, MD, FRCPC, MCGill University, Douglas Mental Health University Institute, Montréal, Quebec, Canada \\ Correspondence: Ashok Malla, Department of Psychiatry, Douglas Mental Health University Institute, ACCESS-Canada Pavilion, 6625 LaSalle Boulevard, Montréal, Quebec, H4H 1R3, Canada. Email: ashok.malla@mcgill.ca \\ First received 22 Sep 2016, final revision 10 Dec 2016, accepted 27 Jan 2017}

\section{Funding}

D.L. is funded through a Fonds de recherché du Quebec - Sante (FRQS) graduate scholarship. G.G. is funded for a postdoctoral fellowship through the Canadian Institutes for Health Research (CIHR). A.M. is funded through the Canada Research Chairs Program (CRC). Funding agents were not involved in any aspect of this review's construction and submission.

\section{Acknowledgements}

We would like to thankfully acknowledge the incredible assistance of McGill's librarian Pamela Harris and to the painstaking coding conducted by Shruthi Venkataraman.

\section{References}

1 Ho BC, Nopoulos P, Flaum M, Arndt S, Andreasen NC. Two-year outcome in first-episode schizophrenia: predictive value of symptoms for quality of life. Am J Psychiatry 1998; 155: 1196-201.

2 Rabinowitz J, Levine SZ, Garibaldi G, Bugarski-Kirola D, Berardo CG, Kapur S. Negative symptoms have greater impact on functioning than positive symptoms in schizophrenia: analysis of CATIE data. Schizophr Res 2012; 137: 147-50. 
3 Jordan G, Lutgens D, Joober R, Lepage M, Iyer SN, Malla A. The relative contribution of cognition and symptomatic remission to functional outcome following treatment of a first episode of psychosis. Clin Psychiatry 2014; 75 e556-72.

4 Carpenter WT, Heinrichs DW Wagman AMI. Deficit and nondeficit forms of schizophrenia - the concept. Am J Psychiatry 1988; 145: 578-83.

5 Malla AK, Takhar JJ, Norman RM, Manchanda R, Cortese L, Haricharan R, et al. Negative symptoms in first episode non-affective psychosis. Acta Psychiatr Scand 2002; 105: 431-9.

6 Kirkpatrick B, Buchanan RW, Ross DE, Carpenter WT Jr. A separate disease within the syndrome of schizophrenia. Arch Gen Psychiatry 2001; 58: $165-71$.

7 Buchanan RW. Persistent negative symptoms in schizophrenia: an overview. Schizophr Bull 2007; 33: 1013-22.

8 Arango C, Garibaldi G, Marder SR. Pharmacological approaches to treating negative symptoms: a review of clinical trials. Schizophr Res 2013; 150: 346-52.

9 Buchanan RW, Kreyenbuhl J, Kelly DL, Noel JM, Boggs DL, Fischer BA, et al The 2009 schizophrenia PORT psychopharmacological treatment recommendations and summary statements. Schizophr Bull 2010; 36: 71-93.

10 National Collaborating Centre for Mental Health. Schizophrenia-Core Interventions in the Treatment and Management of Schizophrenia in Primary Care. NICE, 2002.

11 Pilling S, Bebbington $\mathrm{P}$, Kuipers E, Garety $\mathrm{P}$, Geddes J, Orbach G, et al. Psychological treatments in schizophrenia: I. Meta-analysis of family intervention and cognitive behaviour therapy. Psychol Med 2002; 32 763-82.

12 Vancampfort $D$, Probst $M$, Helvik Skjaerven $L$, Catalán-Matamoros $D_{\text {, }}$ Lundvik-Gyllensten A, Gómez-Conesa A, et al. Systematic review of the benefits of physical therapy within a multidisciplinary care approach for people with schizophrenia. Phys Ther 2012; 92: 11-23.

13 Jauhar S, McKenna PJ, Radua J, Fung E, Salvador R, Laws KR. Cognitivebehavioural therapy for the symptoms of schizophrenia: systematic review and meta-analysis with examination of potential bias. Br J Psychiatry 2014 204: 20-9.

14 Bird V, Premkumar P, Kendall T, Whittington C, Mitchell J, Kuipers E. Early intervention services, cognitive-behavioural therapy and family intervention in early psychosis: systematic review. Br J Psychiatry 2010; 197: 350-6.

15 Fusar-Poli P, Papanastasiou E, Stahl D, Rocchetti M, Carpenter WT, Shergill S, et al. Treatments of negative symptoms in schizophrenia: meta-analysis of 168 randomized placebo-controlled trials. Schizophr Bull 2015; 41: 892-9.

16 Elis O, Caponigro JM, Kring AM. Psychosocial treatments for negative symptoms in schizophrenia: current practices and future directions. Clin Psychol Rev 2013; 33: 914-28.

17 Evidence Partners. DistillerSR. Evidence Partners, 2011.

18 Pai M, McCulloch M, Gorman JD, Pai N, Enanoria W, Kennedy G, et al. Systematic reviews and meta-analyses: an illustrated, step-by-step guide. Natl Med J India 2003; 17: 86-95.

19 Guyatt G, Rennie D. Users' Guides to the Medical Literature: A Manual for Evidence-Based Clinical Practice, Vol 706. AMA Press, 2002.

20 Centre for Reviews and Dissemination. Undertaking Systematic Reviews of Research on Effectiveness: CRD's Guidance for Carrying Out or commissioning Reviews. NHS Centre for Reviews and Dissemination, 2001

21 Higgins JP, Green S. Cochrane Handbook for Systematic Reviews of Interventions, Vol 5. Wiley Online Library, 2008.

22 Sedgwick P, Marston L. Meta-analyses: standardised mean differences. BMJ 2013. 347: f7257.

23 Moher D, Liberati A, Tetzlaff J, Altman DG; PRISMA Group Preferred reporting items for systematic reviews and meta-analyses: the PRISMA statement. Ann Intern Med 2009; 151: 264-9.

24 Farhall J, Freeman NC, Shawyer F, Trauer T. An effectiveness trial of cognitive behaviour therapy in a representative sample of outpatients with psychosis. Br J Clin Psychol 2009; 48: 47-62.

25 Granholm E, Holden J, Link PC, McQuaid JR. Randomized clinical trial of cognitive behavioral social skills training for schizophrenia: improvement in functioning and experiential negative symptoms. J Consult Clin Psychol 2014 82: 1173-85.

26 Gumley A, O'Grady M, McNay L, Reilly J, Power K, Norrie J. Early intervention for relapse in schizophrenia: results of a 12-month randomized controlled trial of cognitive behavioural therapy. Psychol Med 2003; 33: 419-31.

27 Jackson H, McGorry PD, Killackey E, Bendall S, Allott K, Dudgeon P. Acutephase and 1-year follow-up results of a randomized controlled trial of CBT versus befriending for first-episode psychosis: the ACE project. Psychol Med 2008; 38: 725-35
28 Klingberg S, Wittorf A, Fischer A, Jakob-Deters K, Buchkremer G, Wiedemann G. Evaluation of a cognitive behaviourally oriented service for relapse prevention in schizophrenia. Acta Psychiatr Scand 2010; 121 $340-50$

29 Klingberg S, Wölwer W, Engel C, Wittorf A, Herrlich J, Meisner C, et al. Negative symptoms of schizophrenia as primary target of cognitive behavioral therapy: results of the randomized clinical TONES study. Schizophr Bull 2011; 37 (suppl 2): S98-110.

30 Morrison AP, Turkington D, Pyle M, Spencer H, Brabban A, Dunn G, et al. Cognitive therapy for people with schizophrenia spectrum disorders not taking antipsychotic drugs: a single-blind randomised controlled trial. Lancet 2014; 383: 1395-403.

31 Sensky $T$, Turkington $\mathrm{D}$, Kingdon D, Scott JL, Scott J, Siddle R, et al A randomized controlled trial of cognitive-behavioral therapy for persistent symptoms in schizophrenia resistant to medication. Arch Gen Psychiatry 2000; 57: 165-72.

32 Turkington D, Kingdon D, Rathod S, Hammond K, Pelton J, Mehta R. Outcomes of an effectiveness trial of cognitive-behavioural intervention by mental health nurses in schizophrenia. Br J Psychiatry 2006; 189 $36-40$

33 Turkington D, Kingdon D. Cognitive-behavioural techniques for general psychiatrists in the management of patients with psychoses. Br J Psychiatry 2000; 177: 101-6.

34 Malik N, Kingdon D, Pelton J, Mehta R, Turkington D. Effectiveness of brief cognitive-behavioral therapy for schizophrenia delivered by mental health nurses: relapse and recovery at 24 months. J Clin Psychiatry 2009; 70: 201-7.

35 Barrowclough C, Haddock G, Lobban F, Jones S, Siddle R, Roberts C, et al. Group cognitive-behavioural therapy for schizophrenia. Br J Psychiatry 2006; 189: $527-32$.

36 Cather C, Penn D, Otto MW, Yovel I, Mueser KT, Goff DC. A pilot study of functional cognitive behavioral therapy (fCBT) for schizophrenia. Schizophr Res 2005; 74: 201-9.

37 Drury V, Birchwood M, Cochrane R, Macmillan F. Cognitive therapy and recovery from acute psychosis: a controlled trial. I. Impact on psychotic symptoms. Br J Psychiatry 1996; 169: 593-601.

38 Drury V, Birchwood $M$, Cochrane R. Cognitive therapy and recovery from acute psychosis: a controlled trial. Br J Psychiatry 2000; 177: 8-14.

39 Grant PM, Huh GA, Perivoliotis D, Stolar NM, Beck AT. Randomized trial to evaluate the efficacy of cognitive therapy for low-functioning patients with schizophrenia. Arch Gen Psychiatry 2012; 69: 121-7.

40 Hall PL, Tarrier N. The cognitive-behavioural treatment of low self-esteem in psychotic patients: a pilot study. Behav Res Therapy 2003; 41: 317-32.

41 Kråkvik B, Gråwe RW, Hagen R, Stiles TC. Cognitive behaviour therapy for psychotic symptoms: a randomized controlled effectiveness trial. Behav Cogn Psychother 2013; 41: 511-24.

42 Leclerc $\mathrm{C}$, Lesage AD, Ricard N, Lecomte T, Cyr M. Assessment of a new rehabilitative coping skills module for persons with schizophrenia. Am J Orthopsychiatry 2000; 70: 380-8.

43 Lecomte T, Leclerc C, Wykes T. Group CBT for early psychosis-are there still benefits one year later? Int J Group Psychother 2012; 62: 309-21.

44 Lecomte $\mathrm{T}$, Leclerc $\mathrm{C}$, Corbière $\mathrm{M}$, Wykes $\mathrm{T}$, Wallace $\mathrm{CJ}$, Spidel $\mathrm{A}$ Group cognitive behavior therapy or social skills training for individuals with a recent onset of psychosis? Results of a randomized controlled trial. J Nerv Ment Dis 2008; 196: 866-75.

45 Li ZJ, Guo ZH, Wang N, Xu ZY, Qu Y, Wang XQ, et al. Cognitive-behavioura therapy for patients with schizophrenia: a multicentre randomized controlled trial in Beijing, China. Psychol Med 2015; 45: 1893-905.

46 Lincoln TM, Ziegler $\mathrm{M}$, Mehl S, Kesting ML, Lüllmann E, Westermann $\mathrm{S}$, et al. Moving from efficacy to effectiveness in cognitive behavioral therapy for psychosis: a randomized clinical practice trial. J Consult Clin Psychol 2012; 80: $674-86$

47 Naeem F, Saeed S, Irfan M, Kiran T, Mehmood N, Gul M, et al. Brief culturally adapted CBT for psychosis (CaCBTp): a randomized controlled trial from a low income country. Schizophr Res 2015; 164: 143-8.

48 Peters $E$, Landau $S$, Mccrone $\mathrm{P}$, Cooke $\mathrm{M}$, Fisher $\mathrm{P}$, Steel $\mathrm{C}$, et al. A randomised controlled trial of cognitive behaviour therapy for psychosis in a routine clinical service. Acta Psychiatr Scand 2010; 122: 302-18.

49 Rector NA, Seeman MV, Segal ZV. Cognitive therapy for schizophrenia: a preliminary randomized controlled trial. Schizophr Res 2003; 63: 1-11.

50 Startup M, Jackson MC, Evans KE, Bendix S. North Wales randomized controlled trial of cognitive behaviour therapy for acute schizophrenia spectrum disorders: two-year follow-up and economic evaluation. Psychol Med 2005; 35: 1307-16. 
51 Tarrier N, Lewis S, Haddock G, Bentall R, Drake R, Kinderman P, et al. Cognitive-behavioural therapy in first-episode and early schizophrenia. Br J Psychiatry 2004; 184: 231-9.

52 Tarrier N, Kinney C, McCarthy E, Humphreys L, Wittkowski A, Morris J. Two-year follow-up of cognitive-behavioral therapy and supportive counseling in the treatment of persistent symptoms in chronic schizophrenia. J Consult Clin Psychol 2000; 68: 917-22.

53 Valmaggia LR, van der Gaag M, Tarrier N, Pijnenborg M, Slooff CJ. Cognitive-behavioural therapy for refractory psychotic symptoms of schizophrenia resistant to atypical antipsychotic medication. Randomised controlled trial. Br J Psychiatry 2005; 186: 324-30.

54 Turkington D, Sensky T, Scott J, Barnes TR, Nur U, Siddle R, et al. A randomized controlled trial of cognitive-behavior therapy for persistent symptoms in schizophrenia: a five-year follow-up. Schizophr Res 2008; 98: 1-7.

55 Bartels SJ, Pratt Sl, Mueser KT, Forester BP, Wolfe R, Cather C, et al. Long-term outcomes of a randomized trial of integrated skills training and preventive healthcare for older adults with serious mental illness. Am J Geriatr Psychiatry 2014; 22: 1251-61.

56 Valencia M, Rascon ML, Juarez F, Murow E. A psychosocial skills training approach in Mexican out-patients with schizophrenia. Psychol Med 2007; 37 1393-402.

57 Roberts DL, Combs DR, Willoughby M, Mintz J, Gibson C, Rupp B, et al. A randomized, controlled trial of Social Cognition and Interaction Training (SCIT) for outpatients with schizophrenia spectrum disorders. $\mathrm{Br} J \mathrm{Clin}$ Psychol 2014; 53: 281-98.

58 Horan WP, Rassovsky Y, Kern RS, Lee J, Wynn JK, Green MF. Further support for the role of dysfunctional attitudes in models of real-world functioning in schizophrenia. J Psychiatr Res 2010; 44: 499-505.

59 Hayes RL, Halford WK, Varghese FT. Social skills training with chronic schizophrenic patients: effects on negative symptoms and community functioning. Behav Ther 1995; 26: 433-49.

$60 \mathrm{Li} \mathrm{F}$, Wang M. A behavioural training programme for chronic schizophrenic patients: a three-month randomised controlled trial in Beijing. Br J Psychiatry 1994; 165 (suppl 24): 32-7.

61 Dobson DJ, McDougall G, Busheikin J, Aldous J. Effects of social skills training and social milieu treatment on symptoms of schizophrenia. Psychiatr Serv 1995; 46: 376-80

62 Xiang Y, Weng Y, Li W, Gao L, Chen G, Xie L, et al. Training patients with schizophrenia with the community re-entry module. Social Psychiatry Psychiatr Epidemiol 2006; 41: 464-9.

63 Lin EC, Chan $\mathrm{CH}$, Shao WC, Lin MF, Shiau S, Mueser KT, et al. A randomized controlled trial of an adapted illness management and recovery program for people with schizophrenia awaiting discharge from a psychiatric hospital. Psychiatr Rehab J 2013; 36: 243-9.

64 Gil-Sanz D, Diego-Lorenzo M, Bengochea-Seco R, Arrieta-Rodríguez M, Lastra-Martínez I, Sánchez-Calleja R, et al. Efficacy of a social cognition training program for schizophrenic patients: a pilot study. Span J Psycho 2009; 12: 184-91.

65 Rus-Calafell M, Gutiérrez-Maldonado J, Ortega-Bravo M, Ribas-Sabaté J, Caqueo-Urizar A, et al. A brief cognitive-behavioural social skills training for stabilised outpatients with schizophrenia: a preliminary study. Schizophr Res 2013; 143: 327-36.

66 Cook S, Chambers E, Coleman JH. Occupational therapy for people with psychotic conditions in community settings: a pilot randomized controlled trial. Clin Rehab 2009; 23: 40-52.

67 Tatsumi E, Yotsumoto K, Nakamae T, Hashimoto T. Effects of occupational therapy on hospitalized chronic schizophrenia patients with severe negative symptoms. Kobe J Med Sci 2011; 57: E145-54.

68 Foruzandeh N, Parvin N. Occupational therapy for inpatients with chronic schizophrenia: a pilot randomized controlled trial. Japan J Nurs Sci 2013; 10 136-41

69 Hansen JP, Østergaard B, Nordentoft M, Hounsgaard L. Cognitive adaptation training combined with assertive community treatment: A randomised longitudinal trial. Schizophr Res 2012; 135: 105-111.

70 Quee PJ, Stiekema AP, Wigman JT, Schneider H, van der Meer L, Maples NJ, et al. Improving functional outcomes for schizophrenia patients in the Netherlands using cognitive adaptation training as a nursing intervention a pilot study. Schizophr Res 2014; 158: 120-5.

71 Bio DS, Gattaz WF. Vocational rehabilitation improves cognition and negative symptoms in schizophrenia. Schizophr Res 2011; 126: 265-9.

72 Farreny $\mathrm{A}$, Aguado J, Ochoa S, Huerta-Ramos E, Marsà F, López-Carrilero R et al. REPYFLEC cognitive remediation group training in schizophrenia: looking for an integrative approach. Schizophr Res 2012; 142: 137-44.

73 Cella $\mathrm{M}$, Reeder $\mathrm{C}$, Wykes $\mathrm{T}$. It is all in the factors: effects of cognitive remediation on symptom dimensions. Schizophr Res 2014; 156: 60-2.
74 Penadés R, Catalán R, Salamero M, Boget T, Puig O, Guarch J, et al. Cognitive remediation therapy for outpatients with chronic schizophrenia: a controlled and randomized study. Schizophr Res 2006; 87: 323-31.

75 Sánchez P, Peña J, Bengoetxea E, Ojeda N, Elizagárate E, Ezcurra J, et al. Improvements in negative symptoms and functional outcome after a new generation cognitive remediation program: a randomized controlled trial. Schizophr Bull 2014; 40: 707-15.

76 Gharaeipour M, Scott B. Effects of cognitive remediation on neurocognitive functions and psychiatric symptoms in schizophrenia inpatients. Schizophr Res 2012; 142: 165-70.

77 Østergaard Christensen T, Vesterager L, Krarup G, Olsen BB, Melau M, Gluud C. Cognitive remediation combined with an early intervention service in first episode psychosis. Acta Psychiatr Scand 2014; 130: 300-10.

78 Vita A, De Peri L, Barlati S, Cacciani P, Deste G, Poli R, et al. Effectiveness of different modalities of cognitive remediation on symptomatological, neuropsychological, and functional outcome domains in schizophrenia: a prospective study in a real-world setting. Schizophr Res 2011; 133: 223-31.

79 Tan S, Zou Y, Wykes T, Reeder C, Zhu X, Yang F, et al. Group cognitive remediation therapy for chronic schizophrenia: a randomized controlled trial. Neurosci Lett 2016; 626: 106-11.

80 Holzer L, Urben S, Pihet S, Jaugey L. A randomized controlled trial of the effectiveness of computer-assisted cognitive remediation (CACR) program in adolescents with psychosis or at high risk of psychosis: short-term and long-term outcomes. Neuropsychiatr Enfance Adolesc 2012; 60: 71.

81 Ahmed AO, Hunter KM, Goodrum NM, Batten NJ, Birgenheir D, Hardison E, et al. A randomized study of cognitive remediation for forensic and mental health patients with schizophrenia. J Psychiatr Res 2015; 68: 8-18.

82 Bellucci DM, Glaberman K, Haslam N. Computer-assisted cognitive rehabilitation reduces negative symptoms in the severely mentally ill. Schizophr Res 2003; 59: 225-32.

83 Nemoto T, Yamazawa R, Kobayashi H, Fujita N, Chino B, Fujii C, et al. Cognitive training for divergent thinking in schizophrenia: a pilot study. Prog Neuropsychopharmacol Biol Psychiatry 2009; 33: 1533-6.

84 Twamley EW, Vella L, Burton CZ, Heaton RK, Jeste DV. Compensatory cognitive training for psychosis: effects in a randomized controlled trial. J Clin Psychiatry 2012; 73: 1212-9.

85 Mueller DR, Schmidt SJ, Roder V. One-year randomized controlled trial and follow-up of integrated neurocognitive therapy for schizophrenia outpatients. Schizophr Bull 2015; 41: 604-16.

86 Eack, SM, Mesholam-Gately RI, Greenwald DP, Hogarty SS, Keshavan MS Negative symptom improvement during cognitive rehabilitation: results from a 2-year trial of cognitive enhancement therapy. Psychiatry Res 2013; 209: $21-6$.

87 Vauth R, Corrigan PW, Clauss M, Dietl M, Dreher-Rudolph M, Stieglitz RD, et al. Cognitive strategies versus self-management skills as adjunct to vocational rehabilitation. Schizophr Bull 2005; 31: 55-66.

88 Ho RT, Au Yeung FS, Lo PH, Law KY, Wong KO, Cheung IK, et al. Tai-chi for residential patients with schizophrenia on movement coordination, negative symptoms, and functioning: a pilot randomized controlled trial. Evid Based Complement Alternat Med 2012; 2012: 923-5.

89 Ikai S, Suzuki T, Uchida H, Saruta J, Tsukinoki K, Fujii Y, et al. Effects of weekly one-hour Hatha yoga therapy on resilience and stress levels in patients with schizophrenia-spectrum disorders: an eight-week randomized controlled trial. J Altern Complement Med 2014; 20: 823-30.

90 Visceglia E, Lewis S. Yoga therapy as an adjunctive treatment for schizophrenia: a randomized, controlled pilot study. J Altern Complement Med 2011; 17: 601-7.

91 Acil A, Dogan S, Dogan O. The effects of physical exercises to mental state and quality of life in patients with schizophrenia. J Psychiatr Ment Health Nurs 2008; 15: 808-15.

92 Manjunath RB, Varambally S, Thirthalli J, Basavaraddi IV, Gangadhar BN. Efficacy of yoga as an add-on treatment for in-patients with functional psychotic disorder. Indian J Psychiatry 2013; 55 (suppl 3): 374-8.

93 Scheewe TW, Backx FJG, Takken T, Jörg F, van Strater ACP, Kroes AG, et al. Exercise therapy improves mental and physical health in schizophrenia: a randomised controlled trial. Acta Psychiatr Scand 2013; 127: 464-73.

94 Varambally S, Gangadhar BN, Thirthalli J, Jagannathan A, Kumar S, Venkatasubramanian $\mathrm{G}$, et al. Therapeutic efficacy of add-on yogasana intervention in stabilized outpatient schizophrenia: randomized controlled comparison with exercise and waitlist. Indian J Psychiatry 2012; 54: 227-32.

95 Loh SY, Abdullah A, Abu Bakar AK, Thambu M, Nik Jaafar NR. Structured walking and chronic institutionalized schizophrenia inmates: a pilot rct study on quality of life. Glob J Health Sci 2015; 8: 238-48.

96 Kaltsatou A, Kouidi E, Fountoulakis K, Sipka C, Theochari V, Kandylis D, et al. Effects of exercise training with traditional dancing on functional capacity 
and quality of life in patients with schizophrenia: a randomized controlled study. Clin Rehab 2015; 29: 882-91.

97 Cassilhas RC, Cassilhas RC, Attux C, Cordeiro Q, Gadelha AL, Telles BA, et al. A 20-week program of resistance or concurrent exercise improves symptoms of schizophrenia: results of a blind, randomized controlled trial. Rev Bras Psiquiatr 2015; 37: 271-9.

98 Crawford MJ, Killaspy H, Barnes TR, Barrett B, Byford S, Clayton K, et al. Group art therapy as an adjunctive treatment for people with schizophrenia: multicentre pragmatic randomised trial. BMJ 2012; 344: e846.

99 Montag C, Haase L, Seidel D, Bayerl M, Gallinat J, Herrmann U, et al. A pilot RCT of psychodynamic group art therapy for patients in acute psychotic episodes: feasibility, impact on symptoms and mentalising capacity. PloS One 2014; 9: e112348.

100 Talwar N, Crawford MJ, Maratos A, Nur U, McDermott O, Procter S. Music therapy for in-patients with schizophrenia. Br J Psychiatry 2006; 189: 405-9.

101 Gold C, Mössler K, Grocke D, Heldal TO, Tjemsland L, Aarre T, et al. Individual music therapy for mental health care clients with low therapy motivation: Multicentre randomised controlled trial. Psychoth Psychosom 2013; 82: 319-31.

102 Ulrich G, Houtmans T, Gold C. The additional therapeutic effect of group music therapy for schizophrenic patients: a randomized study. Acta Psychiatr Scand 2007; 116: 362-70.

103 Tang $W$, Yao X, Zheng Z. Rehabilitative effect of music therapy for residual schizophrenia: A one-month randomised controlled trial in Shanghai. Br J Psychiatry 1994; 164 (suppl 24): 28-34 .

104 Lu SF, Lo CH, Sung HC, Hsieh TC, Yu SC, Chang SC. Effects of group music intervention on psychiatric symptoms and depression in patient with schizophrenia. Complement Ther Med 2013; 21: 682-8.

105 Bradley GM, Couchman GM, Perlesz A, Nguyen AT, Singh B, Riess C. Multiple-family group treatment for English-and Vietnamese-speaking families living with schizophrenia. Psychiatr Serv 2006; 57: 521-30.

106 Wang L, Zhou J, Yu X, Qiu J, Wang B. Psychosocial rehabilitation training in the treatment of schizophrenia outpatients: a randomized, psychosocial rehabilitation training-and monomedication-controlled study. Pak J Med Sci 2013; 29: 597-600.

107 Dyck DG, Short RA, Hendryx MS, Norell D, Myers M, Patterson T, et al. Management of negative symptoms among patients with schizophrenia attending multiple-family groups. Psychiatr Serv 2000; 51: 513-9.

108 Calvo A, Moreno M, Ruiz-Sancho A, Rapado-Castro M, Moreno C Sánchez-Gutiérrez $T$, et al. Intervention for adolescents with early-onset psychosis and their families: a randomized controlled trial. J Am Acad Child Adolesc Psychiatry 2014; 53: 688-696.

109 Buchkremer G, Klingberg S, Holle R, Schulze Mönking H, Hornung WP, et al. Psychoeducational psychotherapy for schizophrenic patients and their key relatives or care-givers: results of a 2-year follow-up. Acta Psychiatr Scand 1997; 96: 483-91.

110 Cai J, Zhu Y, Zhang W, Wang Y, Zhang C. Comprehensive family therapy: an effective approach for cognitive rehabilitation in schizophrenia. Neuropsychiatr Dis Treat 2015; 11: 1247-53.

111 Cai C, Yu L, Rong L, Zhong H. Effectiveness of humor intervention for patients with schizophrenia: a randomized controlled trial. J Psychiatr Res 2014; 59: 174-8.

112 Gelkopf M, Gonen B, Kurs R, Melamed Y, Bleich A. The effect of humorous movies on inpatients with chronic schizophrenia. J Nerv Ment Dis 2006 194: 880-3.
113 Thorup A, Petersen L, Jeppesen $\mathrm{P}$, Ohlenschlaeger J, Christensen $T$, Krarup G, et al. Integrated treatment ameliorates negative symptoms in first episode psychosis-results from the Danish OPUS trial. Schizophr Res 2005; 79: 95-105.

114 Garety PA, Craig TKJ, Dunn G, Fornells-Ambrojo M, Colbert S, Rahaman N, et al. Specialised care for early psychosis: symptoms, social functioning and patient satisfaction. Randomised controlled trial. Br J Psychiatry 2006; 188: $37-45$.

115 White R, Gumley A, McTaggart J, Rattrie L, McConville D, Cleare S, et al. A feasibility study of acceptance and commitment therapy for emotional dysfunction following psychosis. Behav Res Therapy 2011; 49: 901-7.

116 Röhricht F, Priebe S. Effect of body-oriented psychological therapy on negative symptoms in schizophrenia: a randomized controlled trial. Psychol Med 2006; 36: 669-78.

117 Villalta-Gil V, Roca M, Gonzalez N, Domenec E, Ana Escallani, C, Asensio MR, et al. Dog-assisted therapy in the treatment of chronic schizophrenia inpatients. Anthrozoös 2009 22: 149-59.

118 Anderson KH, Ford S, Robson D, Cassis J, Rodrigues C, Gray R. An exploratory, randomized controlled trial of adherence therapy for people with schizophrenia. Int J Ment Health Nurs 2010; 19: 340-9.

119 Gholipour A, Abolghasemi Sh, Gholinia K, Taheri S. Token reinforcement therapeutic approach is more effective than exercise for controlling negative symptoms of schizophrenic patients: a randomized controlled trial. Int J Prevent Med 2012; 3: 466-70.

120 Choi J, Medalia A. Intrinsic motivation and learning in a schizophrenia spectrum sample. Schizophr Res 2010; 118: 12-9.

121 Bertelsen M, Jeppesen P, Petersen L, Thorup A, øhlenschlaeger J, le Quach $\mathrm{P}$, et al. Five-year follow-up of a randomized multicenter trial of intensive early intervention vs standard treatment for patients with a first episode of psychotic illness: the OPUS trial. Arch Gen Psychiatry 2008; 65: 762-71.

122 Singh SP, Evans N, Sireling L, Stuart H. Mind the gap: the interface between child and adult mental health services. Psychiatrist 2005; 29: 292-4.

123 Erekson DM. Scheduled Healing: The Relationship between Session Frequency and Psychotherapy Outcome in a Naturalistic Setting (PhD). Department of Psychology, Brigham Young University, 2013 (http:// scholarsarchive. byu.edu/cgi/viewcontent. cgi? article $=5036 \&$ context $=$ etd).

124 Garety PA, Fowler D, Kuipers E. Cognitive-behavioral therapy for medication-resistant symptoms. Schizophr Bull 2000; 26: 73-86.

125 Ayllon T, Azrin N. The Token Economy: A Motivational System for Therapy and Rehabilitation. Appleton-Century-Crofts, 1968.

126 Frank AF, Gunderson JG. The role of the therapeutic alliance in the treatment of schizophrenia: Relationship to course and outcome. Arch Gen Psychiatry 1990; 47: 228-36.

127 Bellack AS, Mueser KT, Gingerich S, Agresta J. Social Skills Training for Schizophrenia: A Step-by-Step Guide, 2nd edn. Guilford Publications, 2013.

128 Green MF. Cognitive remediation in schizophrenia: is it time yet? Am J Psychiatry 1993; 150: 178-87.

129 Ryan RM, Plant RW, O'Malley S. Initial motivations for alcohol treatment: relations with patient characteristics, treatment involvement, and dropout. Addict Behav 1995; 20: 279-97.

130 Erhart SM, Marder SR, Carpenter WT. Treatment of schizophrenia negative symptoms: future prospects. Schizophr Bull 2006; 32: 234-7.

131 Kirkpatrick B, Fenton WS, Carpenter WT Jr, Marder SR. The NIMH-MATRICS consensus statement on negative symptoms. Schizophr Bull 2006; 32 : $214-9$ 